\section{Seeking, Negotiating, and \\ Generating Common Ground. Microanalyses of Communication Dynamics with a View to Emergent Cooperation}

\author{
Kéri Rita \\ Corvinus University of Budapest, Institute of Behavioural Sciences and \\ Communication Theory, Doctoral School of Social Communication, Hungary
}

\begin{abstract}
The paper presents a field study that looked at teaching contexts as instances of joint knowledge construction. The study was part of a larger enterprise in the vein of grounded theory, exploring qualitative connections between communication dynamics and evolving cooperation patterns, aiming to provide feedback to theories on the overall relationship between communication and cooperation. This study also involved looking at the joint problem definition and planning in groups of adults with different sociocultural backgrounds. In the kinds of settings selected, participants are likely to start with diverging strategies and axioms used in articulating knowledge. Comparative analyses of formal and extracurricular teaching situations are presented in the paper, and their implications are explained in the conceptual framework of common ground, private experience, and public knowledge products. The focus is on the communicative context, the role that verbal contributions and interpersonal strategies play in jointly framing a problem: how different dimensions of communication complement or interfere with each other to serve the purposes of local and long-term coordination and knowledge production, and meanwhile shape the community. In the preliminary theoretical considerations governing the study, I aimed to develop a perspective that enables the exploration of the types of situations selected, and this has been refined to give meaningful analysis of such situations. I am presenting strategies that simultaneously shape cooperative potential and construct the means that enable joint action and limit its form, involving the creative mobilization of private worlds.
\end{abstract}

Keywords: verbal and non-verbal interaction, common ground, communication, teaching, coordination, private and public

\footnotetext{
Address for Correspondence: Kéri Rita, email: keririta[at]yahoo.com

Article received on the 25th August, 2016. Article accepted on the 1st December, 2016.

Conflict of Interest: The author declares no conflicts of interest.
}

Acknowledgement: I would like to thank two anonymous reviewers for their valuable critique, remarks, and suggestions, which were a great help in drawing up the present form of the paper. I am also grateful to the schools and the artist Katalin Soós for enabling and supporting my observations. 


\section{Introduction}

\section{Aim of the study, theoretic background}

The study presented in the paper was motivated by my interest in exploring joint planning, community action, and the generation of common knowledge in situations where participants come from different sociocultural backgrounds and represent diverging, even incompatible schemes for defining problems and organizing knowledge. Due to these characteristics, such situations represent high levels of uncertainty for the success and prospects of cooperation. The fieldwork results analyzed in this paper are part of a larger study conducted in a process that is in line with the method of grounded theory (Glaser 1965). The specific contexts chosen are also connected to cross-cultural sensitivities and enduring social problems which are left intact or are reproduced by macro-scale processes of change, and the situations analyzed are events where handling such enduring problems is one important aspect of the activities in question. The paper presents a systematic comparison of formal (regular) and extracurricular teaching situations, which were part of a bigger study that comprised fieldwork conducted in teaching situations, as well as in situations aimed at joint project planning and generating informal supportive networks. I focused on ways in which communicative factors at the interpersonal level affected the emergence of a newly shared framework of knowledge and cooperation. At a most general level, I sought to describe and explain instances where more complex problem definitions and bases of cooperation are not found but emerge, not as fixed frameworks (not, e.g., by the selection of a dominant individual's preferred framework), but as defined in social interaction.

The overall goal of the larger study was to provide feedback from fieldwork to theorizing about cooperation and various qualitative aspects of its relationship to communication. Therefore, the questions and hypotheses governing the study are articulated against an interdisciplinary background, drawing on and developing specific theories of communication, joint action, cooperation, trust, and change. I was interested in whether, and to what extent, permanent or stable changes in knowledge structures can launch based on interpersonal dynamics, as bottom-up processes, and what role such processes can play in the emergence of innovations in a coordination system, or in the emergence of new coordination systems. All of the theories I rely on provide important insights to my explanations, but none of them could fully account for the emergence of joint problem definitions in an interpersonal setting. The school study has been a first step towards formulating an extension of these approaches that better accounts for emergence and transformation in situations involving a higher degree of uncertainty. While the traditional conception of formal education as knowledge transfer lends itself to being grasped by the conception of communication as information transfer, here I am taking a different perspective that is in line with the constructivist view and looks at teaching situations as instances of generating common knowledge. While the dynamics explored by the study could be relevant in any teaching situation, schools with mostly disadvantaged students were chosen because a higher degree of uncertainty might be expected in these situations due to the sociocultural gap.

Cooperation has been at the heart of communication theories since Grice (1975), and there has been a shift from explaining it as a maxim or rule towards more compelling arguments that see it as an inherent assumption in cognitive processes triggered by communication (Sperber and Wilson 1986) or as the motive of uniquely human communication (Tomasello 2008). Relying on Grice's initial conceptualization as a presumed or desirable attitude by the speaker, a set of rules that support efficient communication, Sperber and Wilson (1986) offer a theory in the cognitivist vein, assuming the presence of specialized cognitive processes in human communication. They draw on the principle of cooperation, but stress the importance of 
inferences, the reading of intention, and a mutually available cognitive context. Their account rests on the notion that cognitive processes are geared at enhancing knowledge about the world. Clark and Brennan (1991) point out the importance of common ground and describe the processes involved in finding it in interpersonal situations. Their explanations take common ground for granted, available, and only to be agreed on in a given communicative act. In addition to some logical difficulties that this assumption stumbles on (as explained by Sperber and Wilson 1986), I am also arguing that common ground may not be available in any given situation and for any given content, and this is especially relevant in the situations I am dealing with. Sperber and Wilson offer a complex account with the ambition of universal scope. They operate with the concept of cognitive context, which is more the product of the interaction and more flexible. According to this explanation, when perceiving a situation as communicative, an automatism is triggered and this determines the receiver's cognitive processes at a profound level. The receiver will assume cooperation on behalf of the speaker, and her own cooperative stance involves the reading of intentions (especially the intention to inform), inferences, and interpreting the utterance within the communicative context mutually available to the participants. The assumption of such deterministic processes may raise a number of questions: whether there is always a single best context emerging for the cognitive processes; what happens if no context is found to be in line with the aim of extending knowledge; and whether the choice of context and the effort put into processing solely depends on the automatic processes the authors assume to be triggered by communication.

Tomasello's conception of human communication rests on an argument that is, in a sense, the inverse of the above: here, cooperation is the end, the motivation of uniquely human communication (Tomasello 2008). He stresses the importance of certain cognitive capacities, like understanding joint intentions; the ability to represent complementary actions, roles and goal hierarchies leading to a common goal; and the ability to take alternate roles during the process of attaining a goal. The underlying mechanisms that motivate humans for engaging in these special interactions with others, and are present in infants, include monitoring the activity of the other and reacting in an alternating manner (social contingency), as well as mirroring and sharing emotional states in diverse ways (Tomasello 2005).

While the approaches summed up here have provided some important aspects for grasping and analyzing the processes I observed as instances of emergent cooperation and knowledge construction, the assumptions questioned here do not seem to account for all aspects of the kinds of events I chose to study: ones where the basis for common knowledge might be a matter of choice, be questioned or contested, or an element of uncertainty or indefiniteness is involved. One might need an alternative view, in which the nature of the cognitive processes can depend on other factors in the communicative situation, such as perceived cooperative potential.

Taking into consideration the above approaches and some additional perspectives that I sum up in the next paragraphs, the conception of communication that I found useful in analyzing my observations is in line with Horányi's (2009) conceptualization of the communicative as geared at integrating individuals into some community. This general framework supports a flexible view of cooperation principles and intentions, which is desirable for grasping the phenomena of change and uncertainty that we can count on in this setting. It does not presume a coherence of common knowledge and frames. Whatever is publicly presented in a scene of communication may be fitted in a shared meshwork of meanings, and adaptation to a coherent meshwork may be a matter of constitutive processes, while weak alignments and contradictions might also be sustained. On the other hand, coherence or the presence of common horizons for knowledge does not automatically entail a matching of more general cooperation principles.

On the other side, explanations of human cooperative action offered by game theoretic approaches base their explanations on the momentum of taking decisions about cooperating, 
and on the kinds of problems with relation to which cooperative decisions are taken (e.g., Gintis 2009). Norms and other coordination systems are explained as a way of reducing the amount of computation necessary for taking everyday decisions in this paradigm (Simon 1982, cited by several authors, e.g., Gintis 2009, Good 1988). On the other hand, evolutionary explanations focus on the fact that these coordination systems are specific to groups of people (Kurzban \& Neuberg 2005; Haselton et al. 2005). However, all these accounts handle frameworks of strategic decisions that are fixed, and do not account for cases when decisions to change the framework are taken, or for how problems can be seen as malleable in processes involving social action. Decisions to take cooperative action are taken to be in close relationship with trust, and are in fact often taken to be identical with it in experimental paradigms (Gintis 2009). In this approach, decisions about cooperation are seen as made in a solitary mind, and experimental studies in this paradigm are often conducted in anonymity, without the partners communicating with each other. Studies where communication is allowed reveal connections between cooperative decisions and a limited, though widening range of factors, like the ability to make verbal agreements and promises or the richness of the medium of communication (Sally 1995, cited by Gintis 2009, Balliet 2010). The present study represents a perspective that points towards a different grasp of this relationship, involving profound changes at the level of semantics.

Several authors have explored the way trust is entwined with the social context and the way levels of trust are dependent on it (Fukuyama 1995; Tilly 2005; Luhmann 1988). These accounts also operate with a stable social context, while explanations of social change speak about dramatic processes or turns (Turner 1974; Cosmides and Tooby 1992), rather than slower paced small scale processes. The situations I am dealing with are often also laden with conflict, but also imply different problematics and possibilities, raising the question of how (or whether) permanent and stable change in cooperation systems can emerge in such circumstances. I owe some aspects of my analyses to Victor Turner's (1969) explanations of the dynamics of stability and change, and the sense in which I am using the term connectivity in this paper draws on his concept of communitas. Specific anthropological analyses, such as one explaining the ways symbolic systems foster connection and change and mediate between the private and the public worlds (Obeyesekere 1981), as well as a decision-theoretic account of how public representations and awareness of joint perception affects decisions (Chwe 2001), have also inspired the study, although these works explain a different scope of events, and the dynamics are different in many respects.

In addressing the question of coordination, the game theoretic approach operates with a definition of common knowledge formulated by Lewis (1969). This conception of common knowledge has a strict propositional form: it is expressed as mutual beliefs of facts and beliefs about the beliefs of other actors about the same facts. In this sense, common knowledge drives mutual expectations about the behaviors of others, and is the basis of conventions that ensure the coordination of actions in certain cases to serve the mutual benefit of the actors in cases where several alternative actions may lead to mutually favorable solutions. Lewis identifies the sources of such expectations as agreements, salience or precedent. As I pointed out earlier, the game theoretic explanations mobilize this definition in models where the problem is seen as pre-existing the act of coordination, that is, in a model that is applicable to stabilized social environments. As several authors point out, the emergent aspect of social coordination, remain unexplained in this framework (Gintis 2009; Binmore 1994). Therefore, the study of teaching contexts - among other situations - as instances of knowledge generation can be expected to add insights for exploring this question and extending the existing theories with this aspect. By a critical treatment of these theories, I was looking for a framework in which it is possible to grasp, describe, and reflect on situations where cooperation is sought and joint activity persists when no jointly agreed problem definition pre-exists. As an initial hypothesis, I 
proposed a view of interpersonal communication in which the shaping of social connections and the sizing up of cooperative potential are just as important as cognitive gain (as defined by Sperber and Wilson 1986), and these two aspects are interdependent, rather than one being reducible to the other. I was working towards a view according to which communication punctuates the flow of private and joint experiences, with points of joint reference emerging, to a certain degree, on a trial and error basis, and diverse factors in the communicative event affect joint choices. I assumed that every communicative situation could involve an element of testing the degree of community or cooperative potential and experimenting with tried or potential coordination tools.

Importantly also, activities involving communication can be seen as instances of mediating between private experience and the public domain, as well as setting and eliminating social relations and boundaries, and enabling the arrangement of social space in a finely tuned manner. The private and the public are seen as intertwined: learning from, with and about others, as well as aside from and for community is taking place at the same time. Generating cooperative potential is considered to be an important drive, and possible cooperative frameworks are inseparable from the structuring of portable common knowledge.

Knowledge patterns can be specific to certain groups or persons, without the users necessarily reflecting on this, and these patterns may build on axioms that are potentially incommensurable with axioms of other systems. Thus, in processes of major change or consensus-seeking, structures and familiar frames of interpretation or joint reference may be disrupted, and I assumed that supportive strategies would involve offering and seeking continuity, stable points that can serve as links between private experience and its community setting, while the overall structures are in formation. For the purposes of the present argument, I have defined common ground in a very broad sense: as any aspect of the communicative context, either pre-existing or locally found, that might emerge as a basis for a sense of community (or connectivity) for the participants: any aspect of the situation that participants can use as a common starting point to build on in generating common knowledge or joint problem definitions.

By asking questions based on the above outlines, I expected to be able to characterize meaningful structural differences between formal and extracurricular teaching situations, and give explanations for emerging difficulties, conflict or halting in both the former and the latter. I hypothesized that formal and extracurricular settings would show differences in the ways content for common knowledge is offered, approved and incorporated, and in the ways the teaching events are (or become) embedded in wider cooperation contexts and systems. The expectation was that adjustment of the theories would be justified if this framework could provide useful insight into the dynamics behind the observed events, and if the structural differences explored would account for differences in the patterns of conflict, halting or crisis in the two types of situations.

\section{Field study in the school settings}

\section{The context}

The greater part of the school study took place during a two-year period and comprised the observation of formal and extracurricular teaching events. Formal teaching events were observed in a public school in Budapest, educating students of ages 6 to 14, in an area with a high proportion of Roma residents. The majority of the classroom observations was made in two classes with students aged 10-16, with several different subject teachers. The extracurricular teaching events were art workshops that took place with groups of Roma 
children at two locations and were all held by the same artist and her variable crew. The two locations were another public school and a neighboring community center in the same area, where the workshops involved mostly Roma students from the public school. The context outside the actual teaching situations was also extensively studied and is taken into account in the analyses to the degree that seems relevant to the subject.

As I pointed out in the introduction, an important characteristic of both types of settings chosen is the sustained uncertainty and a kind of extended transitional state the community lives in. It is not evident that the teaching content or even this form of teaching is continuous with the children's experiences and expectations, or seems consistent with prevailing or successful life strategies in their environment. Taking a joint framework for granted without reflecting on it can (and often does) preserve incompatible perspectives and leads to stalling or conflict. These general points are equally true and relevant in both the formal and the extracurricular teaching contexts in the Roma communities.

The school and the wider context support the sustenance and reinforcement of cooperative attitudes and a sense of community at many different levels outside the classroom. The sustenance of community at these levels involves a set of rules, regulations, incentives, and sanctions complemented with mostly social caring functions. In the meantime, while dropping out before finishing the first eight grades of education (without obtaining the lowest level "elementary school" qualification) had been very common with the previous generations, parents themselves now often report changes and confirm that there are more positive attitudes to education and its role in their life strategies. This shift is also observed in the school where the formal teaching events were observed - nearly all children are admitted to a trade or vocational secondary school at the end of the 8th grade.

There are two important differences between the two types of settings, which are clear at the outset. The first has to do with the conditions of participation in the teaching events: while both situations are embedded in the social context that generates an overall sense of community around formal education (as described above), this will affect the basics of cooperation in the two types of settings differently. The formal teaching situations are part of compulsory education, while the workshops are optional, and do not lead to obtaining any kind of certificate. Therefore, children's motivations and pressures to participate and stay involved differ in the two settings. The other major difference has to do with the kind of common knowledge expected to evolve because of the teaching process. In the formal education setting, the knowledge structure and elements owned and manifested by the teacher are expected to dominate and be preserved: common knowledge should eventually be manifested by the children with restricted criteria. The extracurricular activities represent greater freedom: they enable a high degree of flexibility and will also support the evolution of different dynamics. In the former case, the task is more that of facilitating connection with institutionalized knowledge while preserving and reproducing its form, and the latter types of situations have a greater potential for the generation of knowledge and the shaping of social space with its own roles and norms at the same time. Both of these differences entail further structural differences, which have been characterized in the framework outlined in the introduction.

\section{Methods and aspects of observation}

Data in the extracurricular teaching setting was collected with participant observation, semistructured interviews, and regular targeted conversations with the lead artist. I visited the weekly art workshops for one semester, paid follow-up visits later on, and made follow-up interviews with the lead artist of the instructor crew. The extracurricular setting was flexible enough to allow me to engage in much interaction with the children during instruction as well 
as outside the workshops, and even facilitate the workshops when it seemed adequate. As participation in the workshops was optional, students fluctuated, with the same 6-10 children of ages 10-14 participating each time. During the semester when I followed the workshops closely, they took place in a classroom in the public school, and later they moved to the neighboring community center, still recruiting students from the same school. Other locations within the school and in the neighborhood were sometimes chosen for shooting videos and taking photos.

Data in the formal setting were collected during three consecutive semesters: a focused study of teaching situations with participant observation began after a preparatory phase, in the second half of the second semester. A total number of 23 teaching classes were observed, 45 minutes each, taught to groups of 8-10 children by a subject teacher supported by one assistant teacher. The subjects taught were mathematics, literature, history, English, (comprehensive) natural science, and drawing. The classroom observations were complemented by interviews with the school staff (one program manager and one program coordinator) about the school's program and their own methods and views; a questionnaire filled by volunteering members of the teaching staff; and ongoing informal conversations with the children as well as the subject teachers and assistant teachers, centered around different aspects of what I had observed in the classroom and during the extracurricular activities, and also in a free flow about topics that concerned them with relationship to the school context. In addition to the formal teaching events, I spent a day with one of the classes in a "forest school" event and participated with them in extracurricular events and morning "discussion circles" held by the assistant teacher responsible for the class, focusing on daily matters.

Apart from observations at the teaching sites, I conducted an extensive exploration of the wider context of the two settings during the two-year period. I met with the families of some of the children participating in the extracurricular workshops as well as other families living in the area (10 families altogether), made interviews with a social worker responsible for the area and obtained information from other community activists, and accompanied the social worker on several visits to families in the neighborhood.

During the observations and the interviews, I used handwritten notes because I aimed at the minimum degree of interference with the events. While the data collected in the wider context provided an important backdrop for the study results, the main focus was on interpersonal communication in the classroom and the extracurricular activities. The analyses of these local interactions are the ones that are relevant to answering the questions raised in the study.

The aim was to collect qualitative data in the teaching situations, based on the focal question of the study: the establishment of common ground and the construction of common knowledge in interpersonal communication. My overall guideline was to look for the general strategies used by teachers as well as students for establishing community, finding common ground, and building common knowledge, with attention to both the verbal and non-verbal aspects and their interplay. As the other side of this dynamic, I also looked at the ways boundaries might be set, attitudes shaped and coordination (along with commitment, community, and cooperation) accepted, neglected or refused. The more specific questions asked at the outset were: how are points of joint reference made mutually available and taken as common ground; who are they manifested by, and how are they accepted (or why are they rejected or neglected) by participants; what sources is the emerging common knowledge, joint problem definition or art product based on: how is a consensual public representation built from the contributions of different participants; [this part is to be rephrased as the sense is unclear] what verbal and nonverbal aspects of communication are brought into play in the process; how does all this shape the structure of community and knowledge: joint, complementary and discrepant perspectives; whether in these situations there is always need for translating and exploring the other's background, or shortcuts can be generated to community and connectivity on the spot; how 
coordination tools emerge as local or portable; what determines whether certain norms, values, frames of reference, etc. are flexible, malleable or rigid; and how consensus is sought and achieved throughout.

\section{Results: Systematic differences between the subject teaching settings and the art workshops}

Some systematic differences of communication observed between the two types of settings are closely related to the overall differences between the settings as outlined above: the desirable kind of common knowledge to be achieved and the conditions of participation. In this section, I first describe and explain the most systematic differences in the sources of knowledge content, the ways it is structured, and the ways connection is made with the children's private worlds, and, more generally, how common ground is sought. Then I go on to more detailed analyses of some situations that are telling as to the difficulties, obstacles and crises arising, and explain these in the framework I proposed in the introduction.

The different conditions of participation in the two settings entail certain structural differences between them. The formal teaching situations are compulsory, and also embedded in a wider institutional framework of cooperation, fulfilling a functional role. As I have pointed out, a great deal of effort is invested by social agents and school staff into reinforcing the pursuit of qualifications as a relevant strategy for Roma families. This is done at different levels, including practical and symbolic aspects of the daily life of students in the school. Short-term objectives are set and regularly reinforced, and a lot of effort is put into maintaining the classroom order. Teachers most often use frontal instruction paired with a theatrical style. Although the extracurricular workshops held in the school setting are also supported to some degree by the same contextual reinforcement, the fact that they are optional also exempts them from it. They are not seen as integral to the same long-term strategy, classroom order is not taken so strictly, and the style of teaching is more casual. These factors turn out to influence the way participants put effort into seeking common ground: offering it and dealing with what is offered. Systematic differences were also found in the types of difficulties, haltings, conflicts, and crises arising in the two types of situations.

\section{Seeking common ground}

One way of finding common ground, starting points for constructing common knowledge is by establishing links between the private worlds of the children and the knowledge product, and this strategy is used in both types of settings. However, the ways it is done in each case differ significantly. In the formal setting, where a well-defined knowledge product is an expectation, finding organic match or basis for common ground requires a greater effort, and there are limitations to how it can be done adequately. The effort is often taken on by teachers, who employ different tools to adjust private experience to knowledge when looking for links between them. They tend to pick and offer what seems appropriate to them, and this is often done by default - they prefer tools that, as they assume, respond to children's experience and beliefs. Such strategies were not typical in the extracurricular workshops, where there are much less restrictions on the desired end result. Exerting content from the children directly is much more common here: instructors offer open and flexible frameworks, and ask for accounts of children's experiences, beliefs, preferences, ideas, while they rarely come up with attributed content. This, in part, also has to do with the subjects taught in each case. However, in comparison with art-related classes in the formal setting, such differences are still marked. As opposed to the formal context, a wide variety of content is often approved in the workshops, 
and children's suggestions rarely meet with rejection or criticism. Such differences may not necessarily characterize all teaching situations in these two types of settings; however, in the observed cases, the ways that difficulties, instability, conflict, halting or crisis arose were different, and had to do with these strategies combined with the nature of uncertainties and indefiniteness in the cooperation system.

Based on the above general differences and strategies by which content is sourced and arranged, ordered and aligned in these two contexts, we might observe that the extracurricular context represents a generative strategy of arriving at common knowledge, with a less elaborate and less restrictive initial frame and the molding of new content sourced from private worlds, and the formal context lends itself better to the conceptualization of common knowledge as filling information gaps within an existing and fixed framework. However, the success of finding connection and adjustment often required the disruption of the fixed framework, and not just the import, if only temporarily, of private knowledge elements in the latter context too.

\section{Difficulty, halting, conflict, and crisis}

In the formal teaching situations, the most typical conflicts or obstacles to success had a local focus, and had to do with the effort needed to keep children engaged: find organic links and sustain willingness and ability to participate in the given situation. Difficulties mostly had to do with either the desirability or the (perceived) feasibility of cooperating and finding meaningful connections locally. In the extracurricular teaching context, instructors put a great emphasis on finding and sustaining links, even loose ones, between children's private worlds and imported knowledge, and connecting was made easy. Technical learning and practice seemed more like a by-product, while great efforts were put into continuously learning about the children and incorporating their content into the products. The result was a wide platform available for finding common ground. The teachers enabled participants to create a pool of shared representations, but that was less structured: the relations, functions, ends, and sometimes even the meanings of these representations (e.g., artworks) remained, to some extent, undefined. Minor local difficulties did arise, but they were casually overcome here, while some major crises and difficulties to proceed with the project as a whole arose due to the undefined nature of the wider cooperative framework: the roles, ends, and potential on the larger scale, beyond the level of the workshops.

In the following sections, I provide more detailed descriptions and some examples for techniques of connecting and the ensuing dynamics, and some cases that demonstrate the different ways in which these lead to halting, conflict or crises and how these are overcome (or not) in the two types of settings respectively.

\section{Analyses: Strategies in the formal setting}

\section{Seeking connection, problems with common ground}

\section{Attributions by teachers}

In general, children's private experiences and preliminary assumptions are treated as a basis for the articulated knowledge in the formal setting, as long as they are considered to be in line with its approved, well-formed manifestation. In most cases, however, this is only true in the phase of learning. Knowledge, as it is expected to be finally manifested by the children, will no longer include the personal elements. The relevant and portable part of the teaching content has to be left intact from personal experience. 
When children's experiences are used as links between material and private world, they are most often attributed rather than exerted in this setting: that is, they are based on the general assumptions of the teacher about children of this age. We could also say that the teacher maintains control over the form of knowledge and relevant ways of connecting and adjusting it to private worlds. This, in turn, affects the kinds of challenges that arise with this strategy.

Many of the subject teachers have little first-hand knowledge of the children's private worlds: they do not interact with them informally as much as assistant teachers, family contact persons, and other support staff. When they resort to examples, they might take certain experiences for granted without checking whether the children actually have them. Being familiar with motorway signs, measurement routines, buying a TV, taking a loan, an experience of oppression or poverty have been imported as examples for a demonstration in explanations of math or history. Some of these experiences the children may be familiar with, others they may not. I have often faced the fact that few of these children ever move out of the district, so many of them are unlikely to ever travel by motorway or be familiar with the zero kilometer stone, which is located in another area of the city.

\section{Difficulties with attributed experiences}

Attributed experiences incorporated into the discussion of certain topics as familiar examples may or may not facilitate engagement, depending on other factors. When the students' perspective is successfully taken or attended to during discourse, relying on attributed experience is a powerful tool for engagement. However, when the teacher is mistaken about children's familiarity with the given experiences or examples are cited without attention to the relevant perspectives, or the perspective is not matched with the appropriate nonverbal style, communication gets cumbersome, and its flow is disrupted. On one occasion, a math teacher cited a mix of examples to make his point, including knowledge that had been a great revelation to him sometime in the past (e.g., the physics of the light bulb). This was accompanied by nonverbal gestures and intonation that would be used with novel and intriguing facts. In fact, this did not seem to correspond to the children's perspective and led to fuzzy orientation and loss of connection with them. In other cases, general enthusiasm on the side of the teacher paired with personalized attentive communication, independent of content, could successfully support creating connectivity at a more general level, which then served as a good basis to build on.

The flow of communication seemed to be supported when nonverbal styles matched the perspectives implied, provided that participants easily adapted to or accepted these perspectives. When importing stories, verbal elements (e.g., the use of personal pronouns, roleplay, "as if" stories) and non-verbal gestures and styles (make-believe, expressions of wonder, attitudes, and emotions) could create or imply an invisible social space, in which children, as well as the teacher, were situated. This, however, was more easily achieved when children's actual experiences were also used as links.

\section{Children's own private experiences - a marginal role}

Explicitly exerting children's own accounts of their experiences has been surprisingly rare in the formal teaching situations. Only in one observed case was the children's private experience directly addressed and linked to the teaching content: a history teacher enquired children about their own stories about religion and linked the discourse to the subject in question (Reformation). By this, she effectively complemented her generally suggestive style and narrative that also relied on emotions and attitudes attributed to the children, which in itself helped them to go with her flow of stories. In general, however, much private experience was shared informally, but mostly with the support staff, as I shall explain later. 
Responding to children's personal requests for content was also rare: an arbitrary request to learn about tattoo motives was fulfilled in an art class, and some content related requests were taken into account in a literature class. This increased children's initial motivation and generated an air in which they were at ease, but it did not in itself secure smooth flow of the related activity throughout. When voluntary accounts of or references to private experiences offered by the children were used as links, they were usually rephrased and adjusted to the desired knowledge frames by the teacher.

Sharing private experiences or extra knowledge for their own sake during class with subject teachers was not frequently initiated on either side. When children were given time for activities that were not an integral part of teaching, the need for engaging with them was often also suspended, or such opportunities were not taken. This happened when a math teacher proposed to share extra subject related skills - to teach one of the more interested students to play MahJong - in the computer lab at the end of instruction: he met with a lack of interest. In the meantime, the children watched YouTube videos of their relatives - musicians, and only the assistant teacher was familiar with or interested in this aspect of their lives. Generally speaking, although subject teachers did mobilize personalized knowledge that they had of the students, institutionalized common knowledge and less formal community were generated at different levels in the school setting, and no continuity was sought or realized between them: the "caring" and the "knowing" functions were separated to a certain degree. This, of course, left a much narrower ground for connecting within the classroom.

\section{Voluntary contributions by children - difficulties and successful strategies}

A typical reason for halting or even conflict was when links were not found between children's contributions and the material. Remarks that can disrupt the flow may be and have been interpreted as willingness to contribute content or just join in or as unwillingness or even hostility, or just difficulty in participating. While attitude reading was frequent and could be more or less successful, a different strategy seemed to be applicable to a number of such cases and has been successful in every instance it was observed. Here are a few examples that demonstrate the dynamics of both strategies.

Some of the teachers attended sensitively to verbal contributions by the children, rephrased and elaborated them, and sometimes even interpreted why some of them would not fit the structure of the knowledge they manifested. However, children's irrelevant contributions were sometimes just interpreted as signs of willingness or unwillingness to get involved. One of the boys with an especially disadvantaged background demonstrated an eagerness for participating and learning. I observed him drop in irrelevant answers on two occasions with two different teachers, who responded to that differently. The first teacher took the student's repeated irrelevant contributions to the history class ("Bastille" and later on "Slovakia" to several different questions in a line) as eagerness to be involved and put more effort into helping him grasp the framework. The other teacher in a literature class interpreted a contribution of 'empty content' ("Something!") as reluctance to collaborate, and reacted to it accordingly. In the latter case, the assistant teacher and I agreed that this interjection was also a sign of willingness. Similar to his remarks in the history class, the interjection could be easily interpreted either as reluctance or as sincere willingness: the boy's style was abrupt and slightly impatient, which could be explained as an intention to contribute paired with helplessness, or as a sign of irritation and a hostile attitude. The teacher explicitly verbalized his own interpretation (that this was a sign of negative attitude - "Because you don't want to [cooperate]"), upon which the boy protested, claiming that his remark might have been taken as a valid answer. In fact, it could actually be seen as an act of offering a wide platform for sharing content, a kind of empty, but common, ground. At the same time, however, it also invited the teacher to take on the 
greater part of the effort. The episode disrupted the flow of the teaching situation and opened up a minor conflict. The conflict was not explicitly clarified on the spot, but a more balanced basis of cooperation was set between the teacher and this student as well as the others later during the class, and I observed a shift in the teacher's strategy towards more exploratory communication and much rephrasing and interpretation of children's contributions in the next semester. He would welcome spontaneous remarks and contributions without immediately reacting to them. This brought into play experiences and links that would probably not have come up as relevant otherwise, such as the notion of the hero as known to children from popular culture, or their free associations on temporality that came up when the theme was the symbolism of seasons. Not all of these were explicitly linked to the content, but they were left "up in the air" nevertheless, and the teacher selected points of reference from them. In fact the restrictions of the adequate form of knowledge and looking for connectivity are forces that produce opposing effects, and they extinguished each other in the case of the boy in the literature class. By letting content stay in an undefined status rather than structuring knowledge at every step. Later on, the teacher helped the generation of space and resources for common ground. This can be seen as an instance of temporarily disrupting the existing knowledge frame, rather than the simple filling of some information gap within the existing framework. As the example of the conflict above demonstrates, such gap filling may sometimes be impossible due to the incompatibility of the existing mutual knowledge frames of the students and the teachers.

A similar strategy was used by a young art teacher during a class of 'initiation': her first time with a group of students, in a rather hostile environment. She patiently and steadily neglected rude provocations, while using other contributions from students to establish common ground and build on it. By neither going with the negative current nor reacting to it, she managed to even out some of the tension, and this helped her to maintain her control of the joint activity. However, this required some initial consensus built on a joint decision about the content to be taught.

Overall, letting free way to children's contributions without immediately adjusting them to some shared structure and using them only as potential sources of common ground was a general strategy that has promoted the flow of communication in several cases. This sometimes involved deselecting certain contributions by just neglecting or adjusting them, as exemplified by the history class.

\section{Connection not sought}

The above examples demonstrate that finding common ground locally requires special strategies and efforts within the structured cooperation framework of formal education. Situations of instruction differ from each other in the ways instruction is done, but there are also cases when common ground is not sought at all or is even rejected when offered, and these situations constitute enduring halting of the knowledge generation process. When some of the students persistently refused to "step on" common ground, to engage with the content by any means, this was invariably attributed by the staff to the low appeal of education and incompatible cooperative commitment: those children came from families that made a living from (sometimes illegal) activities that required no qualification, and they adapted to that life strategy. Such students would not attend classes regularly, and even when they did, they were apparently non-cooperative. One of them felt free to stand up and walk out of the classroom when a minor conflict emerged between him and the teacher during class, and he would never return later during that day. These students would consent to no platform of cooperation either locally or at a more general level, and staff members saw this as an issue that probably remains unresolved as long as they are of school age. 
A language class illustrated a case where it was the teacher who did not clearly initiate or even accept cooperation and community, even though it seemed highly desirable for the children. The teacher apparently represented a role model to the girls in the class in certain respects, especially in her appearance, as a beauty ideal. They kept praising her long, shiny hair, and sought several informal channels of contact, using a very kind tone. In their eyes, her appearance represented a high prestige competence. She either spectacularly neglected the remarks, or just told the children to mind their work. The desks and chairs were arranged in a circular fashion, but no element of the interactions implied joint attention or connectivity. While assigning tasks to pairs of children, the teacher pointed and referred to books and dictionaries, but did not engage in an eye contact or look at the text jointly with them. She was contained and confident, walked around with an upright posture, staying outside the circle of chairs and looking on the students more like an outside observer. She dropped occasional remarks on them to the assistant teacher, disapproving their manners and the way they handled the books ("They do not deserve it"), but not addressing children directly and not even offering a platform for negotiation indirectly (like, for example, saying these things loud enough so the children could protest). Her whole nonverbal style had a character of dignity, confidence, and she kept them at a distance. Probably because her appearance represented high prestige and high desirability of community to the children, they were inclined to adapt to a certain extent: they were much calmer and more controlled than they were in other classes, where teachers initiated community more actively. In a way, their rhythm and behavioral patterns converged on hers, even if this was not really invited. They tuned into her to a certain degree, while she did not tune into them at all. No level of common ground seemed to be acknowledged by her, not even as a potentiality. Content was practically not shared at all; the children were expected to work on their own the whole time. What enabled some level of connectivity was probably the fact that the children put excessive efforts into finding common ground, while she put a lot of effort into avoiding merger (assimilation to any degree on her side), and keeping her world contained. In the meantime, the children showed no sign that they read this as an attitude of rejection. They were helpless with the exercises and frustrated by this, but not by the limited connection. In comparison, open rejection rather than a contained attitude tended to evoke those children's hostility towards other teachers and groups.

The case presents a serendipitous match between values and non-subject skills, and, at the same time, a mismatch between perceptions of the social space, its structure or possible structure, and the desired degree of community. When I discussed this teacher's strategy with the school coordinator, she commented that this was one of the teachers she considered successful because of the way she could get the children to behave. This was a level of success in itself, and the coordinator seemed to have no information about children's subject performance. This limited local connection created by non-verbal tuning might have the potential to support connecting at the level of content, but that did not happen here.

Long-term failure in connecting tends to be related to discrepancies in cooperation systems on a wider scale rather than the lack of common ground locally, and these can be in connection with desirable career goals on both the children's and the teachers' side. For some teachers, working in this school constitutes a challenge, while it certainly does not have a high prestige, and is, therefore, unappealing to others, as it turns out from the questionnaires and conversations with the staff.

\section{Analyses: Strategies in the workshops}

\section{Seeking connection}




\section{Framework and content}

The workshops represent a very different attitude to children's private experiences and their incorporation in the task at hand, which is part of a methodology developed consciously by the instructors to some degree. Private experiences are seen as a desirable resource and an integral part of both the activity and the outcomes. They are not eliminated from the resulting products, but they become a portable and presentable ingredient of common knowledge manifestations. The larger part of the process is the joint activity with the intense involvement of all participants, and usually only certain sub-tasks are done individually. The social space created is a focal element of the activities and is treated more or less reflexively by the teachers, and the final product itself is sometimes a kind of map that also represents the result of the process of shaping the social relations.

The frames available for creating this joint social space are set to some degree by the way the instructors define the tasks. There is usually an artwork produced jointly: a short animated work on video, posters, a comic strip using photos of the children themselves and their artworks, a video piece with the children acting in it. The extent to which this framework is suitable for establishing common ground on the spot varies. Children sometimes take the general definition "work of art" or the more specific genres for granted, and treat them as a kind of sacred entity. At other times they are more inquisitive, even provoke and question the set goal, and sometimes they turn helpless and reluctant. In any case, this overall framework is kept stable throughout the process: once it is agreed on, the instructors never modify it. One might say that it provides the unchanging link with the worlds of the instructors, though the genre is sometimes also the result of a consensus between the instructors and the children. In any case, the framework serves as a kind of structured blank page or empty space that is offered as a most generic common ground - one without content, which the children are free to fill up.

Children can import as much private experience as they wish and can use whatever kind of experience they like, as long as they can adapt to certain expectations of the genre. Continuity with their perspectives is secured by this imported private content. An important fact that shapes the end result is that while teachers bring the framework and the professional skills, children fill it up with a story: matching is facilitated, but teachers' private histories or perspectives are not incorporated into the content. Instructors tend to give tips, suggestions for structural elements. They provide the necessary props, and then facilitate their use. They rarely contribute content of any kind themselves.

The issue of the content adaptability is weighed solely by children, and what they bring in is very rarely rejected. The frameworks are the only normative aspect presented by the teachers. Children are allowed to fill the constructs offered by the instructors very freely, no aesthetic judgement is forced or right ways of doing things are taught as long as the process is working without this. Students fill the frameworks and adapt their experiences and ideas to them, and despite their relatively frequent expressions of helplessness, the events seem to have an even flow and casual atmosphere. In the meantime, when reflecting on these situations, the lead artist reports great difficulties in making them work and a high demand for efforts (preparations, strategizing, coming up with creative ideas and, especially, ways to connect), and she is not always satisfied with the results they achieve. This is partly why she chooses the strategy of continuously extending common ground and improving the potential for common ground: exerting content for its own sake, and keeping up the process while learning about the children. The products become a way of sustaining the process, and the stress put on the end result is decreased with time. The products are not specifically designed for any purpose outside the events themselves.

Relations and style 
Participants freely use their own nonverbal styles. Discipline is rarely an issue, except for outright expressions of aggression. The instructors behave casually, hardly adapting their style and rhythm to the children's: the latter is mostly done only when they face reluctance and try to get someone to perform a task or come up with an idea, or when praising children's products. This convergence of style involves modifying their tone of voice, manner of speaking and body movements to a slight degree, or in a playfully theatrical way, complementing vocabulary borrowed from the children. Aside from these episodic cases of convergence, the general sense of community sometimes seems to be missing for greater involvement and enthusiasm, but the instructors seek other ways to connect: lots of negotiation, occasional teasing, beside the lots of jointly created products. They do not stress their dominant role and authority, but rather they tend not to import and merge their own private worlds either (only their professional expertise).

The flow of communication can be kept up during an average workshop in this manner. The wide space for common ground provides many opportunities to connect, and the task framework is specific enough to provide a joint focus locally. More serious problems tend to arise in the long run, and they take the form of crises, halting for the whole project, rather than conflicts in communication between a teacher and one child on minor issues. If finding matching content for the framework is difficult locally, it is easy to look for alternative ways to proceed, as there are many alternatives for common ground.

\section{Wider perspectives - problems and crises}

The crises that emerged did not happen during the semester in which I observed the workshops in the school setting, but during the time, they were separated in all respects from the system of formal education and were held in the community center. The cases I present here are based on extensive interviews with the lead artist.

Repeated crises emerged because of the uncertainty or misfits in the long-term framework of cooperation. As the workshops are not an integral part of the education system, they are not necessary for obtaining a qualification and do not give formal credits. There is no large-scale institutionalized cooperation system into which they fit, but the possibilities for conceiving or constructing one are wide-ranging. Until this work is done, however, and the consensus is reached and somehow consolidated, there is a high degree of uncertainty in this dimension, and this tended to create ambivalent attitudes to participation, and even distrust or conflict. A very wide common ground was created as a result of long-term interaction, but if it was to become a social context of cooperation potentials at multiple levels, the need to continue jointly structuring knowledge while reflecting on and adjusting perspectives and relations with reference to wider cooperation schemes proved just as important as its availability.

Cases of crisis, halting, and conflict in this setting were due to the lack of long-term perspectives, or the incompatibility of short-term goals, products or the conditions of participation with potential goals and products on the long term or in a wider context. One such case was when one of the participants contributed fictitious content that she claimed to be factual, and a long-term production in the documentary genre was based on it and even launched. Although the fake story could just as well have been used as fictitious content by changing the framework of the product, this was not what happened when the false ground was no longer sustainable. Instead, the girl became reluctant and started to back out from participation on different pretexts. The flow of joint activity was halted because perspectives could not be adjusted to extend the common ground: that would have led to revealing the lie.

A lasting, difficult issue and source of recurring conflict was related to the use of the products beyond the workshops. This issue came up in different forms, highlighting several discrepancies between the perceptions of the participants and the artists of the wider context into which the events and products fit. On one occasion discrepancy of views surfaced relating 
to the criteria by which participants and the artist judged if a product was adequate for presentation: judging by aesthetic criteria, the artist found it inadequate when the participants were willing to present it. At other times general distrust and (mistaken) assumptions about unfavorable ways the products (especially films) could be used by the artists or third parties surfaced, and there was an occasion when a conflict flared up on discrepant views of what aspect of the products constituted value - the work and technical skills invested or the images of the people. Usually, however, it was not necessary to develop tight frameworks of consensus. Demonstrating good intention, showing and proving willingness to participate with symmetrical criteria (even, for example, at the price of discontinuing the photo shoots), or reaching consensus on the overall local aims of the activities (other than presenting the products) and stating their desirability was sometimes enough to proceed.

To sum up the above, efforts by the instructors were invested in extending common ground locally in this setting, and so major conflicts and failure did not arise in this respect: all of the major crises represent perspectives of a wider context. Setting joint goals on a larger scale or even adjusting perspectives to a single unified system was not necessary for consolidating the joint activity, though. Eliminating conflict involved some clarification of perspectives, but connectivity was enough motivation in itself for proceeding. In general, however, if questions are asked about the wider context of cooperation and these are explored, coordination and change can step to a different level, in ways it is not possible in the formal teaching context. This may extend possibilities of common ground to larger structural scales, even if only as a potentiality.

\section{Implications and directions for further study}

The most important findings of the study have revealed major differences between the formal and extracurricular teaching situations. These, as well as difficulties, conflicts, and crises that emerged in both contexts could be explained along the lines proposed at the outset, while some aspects of processes, dynamics that were not expected at the outset were also highlighted.

One of the main implications of the proposed framework in view of the characteristics of the situations, namely, that restrictions on the desirable content and structure of common knowledge narrow down the scope of easily accessible common ground, is almost trivial, and relates to experiences that might be familiar to many. It may not cause grave problems in other contexts, but the study has shown that it does if there is little overlapping between the initial knowledge and general types of experiences of the teachers and the students. Staff members regularly complain that very little of the "transferred knowledge" "goes through" to the children, and they cannot really set high expectations, while this breaks down to minor but frequent difficulties perceived locally on a daily basis, causing conflict and halting the flow of teaching communication in the formal settings. On the other extreme, when the ends of cooperation and knowledge sharing are less defined and there are no significant restrictions on content, a wider space is available for finding common ground, even if little is available initially. This was the case in the extracurricular teaching situations, where major crises emerged on the long run, when there seemed to be a need to define the conditions of participation and potential wider cooperative frames. With regard to the concept of common knowledge, we could say that even in the regulated context of formal education, existing knowledge patterns had to be at least temporarily disrupted in order for connections to be made between private worlds and the presented knowledge forms.

In the analyses of the two types of situations, I have found it useful to introduce the notions of "connectivity" and "structuring" to grasp two aspects of the process of building common knowledge. Connectivity would imply extended potential for common ground, and reflecting 
on and adjusting perspectives and relations would belong to structuring. One of the less explicit initial assumptions of the study has been that these two aspects should be balanced and have equal emphasis on long-term joint activities to work. The findings in the extracurricular context seem to contradict this, and imply that starting with little common ground and wide space for generating knowledge with loose structures, long term joint action can be sustained. The need to define wider perspectives and consolidate trust in some way tended to arise from time to time in the form of crises, but there was no need to settle for a complex cooperation framework or very specific long-term goals and wider perspectives for the process to go on. Though the latter had to be reflected on to some degree, the learning activity attentive to private worlds had enough appeal in itself.

While shaping the community of participants, as it was hypothesized, did seem to be part of manifesting knowledge in both settings, and perspectives had to be adjusted to some degree, both the formal and the extracurricular situations attested that no fixed structure was necessary for smooth joint activities. It did seem to be important though that without attention to different perspectives, the import of experiences as common ground was not possible. When this was attempted, disorientation or misorientation disrupted connectivity and caused helplessness, as demonstrated by examples from a math class in the formal setting, and the unclarified fictitious story in the extracurricular setting.

It has been found that where no adequate common ground was available, different efforts to generate and increase it could be successful. Widening common ground for its own sake was an emphatic pursuit in the extracurricular settings, while some specific strategies were better than others in overcoming difficulties that arose if common ground was not available in the formal settings. What these strategies had in common was that teachers allowed for the temporary presence of different contributions and perspectives from children without immediately interpreting them or relating them to knowledge, and selected the ones that seemed to support the flow of communication and the building of knowledge in some way. In general, each of the two settings put more emphasis on one of the aspects of connectivity and structuring. If the joint process was halted as a result of this bias, paying more attention, if only temporarily, to structuring in the extracurricular setting and to connectivity in the formal setting proved to be ways of promoting the flow. Keeping contributions in a suspended status, "up in the air" in the social space seems to require special effort, as attested by the reported difficulties that the artist-teacher continuously faced, while continuous structuring may render participants helpless with the complexity of perspectives or narrow down the possibilities of common ground to an impossible degree.

Possible continuations of the study include exploring the variety of means used for creating connectivity and for structuring in different settings; the ways these two aspects of joint knowledge creation are employed and interact in successful strategies; some general ways they relate to each other; and ways of reflective planning in practice based on the results. The study also has implications for pedagogy, teaching methodologies, and it can be a basis for comparison with studies of the same or similar social contexts conducted with different methods.

\section{References}

Balliet, D. (2010): Communication and Cooperation in Social Dilemmas: A Meta-Analytic Review. Journal of Conflict Resolution 54(1), 39-57. CrossRef

Chwe, M. S-J. (2001): Rational Ritual: Culture, Coordination and Common Knowledge. Princeton University Press. 
Clark, H. and Brennan, S.E. (1991): Grounding in Communication. In: Resnick, Levine, Teasley (eds.): Perspectives on Socially Shared Cognition (pp. 127-150) Washington, DC Cosmides, L., Tooby, J. (1992): Cognitive Adaptations for Social Exchange In: Barkow, Cosmides, Tooby (eds.): The Adapted Mind. Evolutionary Psychology and the Generation of Culture (pp. 163-228) Oxford University Press.

Fukuyama, F. (1995): Trust. The Social Values and the Creation of Prosperity. New York: Free Press.

Gintis, Herbert (2009): The Bounds of Reason. Game Theory and the Unification of the Behavioral Sciences. Princeton: Princeton University Press.

Glaser, B. G. (1965): The Constant Comparative Method of Qualitative Analysis. Social Problems, 12, 436-45.

Good, D. (1988): Individuals, Interpersonal Relations, and Trust. In: Gambetta, D. (ed.): Trust. Making and Breaking Cooperative Relations. (pp. 31-48) Oxford: Blackwell.

Grice, P. (1975): Logic and Conversation. In D. Davidson and G. Harman (eds) The Logic of Grammar pp. 64-75. Encino, CA: Dickenson.

Haselton et al. (2005): The Evolution of Cognitive Bias. In: Buss, D. M. (ed.): The Handbook of Evolutionary Psychology. New Jersey: John Wiley \& Sons

Horányi, Ö. (2009): Arról, ami szignifikatív és arról, ami kommunikatív; valamint arról, ami problematikus (szinopszis, 7.3 változat). In: Polihistória. Köszöntök és tanulmányok Buda Béla 70. születésnapja alkalmából. (szerk. Bagdy Emőke - Demetrovics Zsolt - Pilling János), Budapest, Akadémiai Kiadó, pp. 201-235. Online: http://ozseb.horanyi.hu/participacio/szinopszis7_3.htm. [last accessed: 1st December 2016]

Kurzban, R., Neuberg, S. (2005): Managing Ingroup and Outgroup Relationships. In: Buss, D. M. (ed.): The Handbook of Evolutionary Psychology pp. 653-675. New Jersey

Luhmann, N. (1988): Familiarity, Confidence, Trust: Problems and Alternatives. In: Gambetta, D. (ed.): Trust. Making and Breaking Cooperative Relations. (pp. 94-108) Oxford: Blackwell.

Obeyesekere, G. (1981). Medusa's Hair: An Essay on Religious Symbols and Personal Experience, Chicago: University of Chicago Press.

Sperber, D., Wilson, D. (1986): Relevance: Communication and Cognition. Oxford: Blackwell. Tilly, Charles (2005): Trust and Rule. Cambridge: Cambridge University Press.

Tomasello, M. (2008). Origins of Human Communication. MIT Press.

Turner, V. (1969): The Ritual Process: Structure and Anti-Structure, Aldine Transaction.

Turner, V. (1974): Dramas, Fields and Metaphors. Symbolic Action in Human Society. Cornell University Press. 